\title{
Spontaneous recanalization of a completely occluded saphenous vein graft two months following acute myocardial infarction with persistent one year patency
}

\author{
Patrick P. Hu · Kirk L. Peterson - Sotirios Tsimikas
}

Published online: 26 April 2009

(c) The Author(s) 2009. This article is published with open access at Springerlink.com

\begin{abstract}
Acute myocardial infarction resulting from saphenous vein graft occlusion occurs not infrequently in patients who have undergone coronary artery bypass graft surgery. In this case report, we present a novel case of spontaneous recanalization of a thrombotic graft occlusion in a patient who presented with a subacute myocardial infarction. The patient was treated medically with aspirin as the only anti-platelet agent. Interestingly, he presented 2 months later with new onset angina. Coronary angiography demonstrated complete resolution of thrombus but a severe focal stenosis in the distal anastomoses. Following drug eluting stent placement, a favorable clinical course has ensued and patency confirmed on follow up angiography at 1 year.
\end{abstract}

Keywords Angioplasty · Drug eluting stent .

Myocardial infarction - Thrombolysis · Fibrinolysis

\section{Introduction}

Approximately 400,000 coronary artery bypass graft (CABG) surgeries are performed in the United States each year [1]. As these grafts age, patients are at high cumulative risk for developing new cardiovascular events due to graft occlusion. Studies have suggested that saphenous vein graft (SVG) occlusion occurs at a rate of approximately

P. P. Hu $\cdot$ K. L. Peterson $\cdot$ S. Tsimikas

Division of Cardiovascular Diseases, University of California,

San Diego, USA

S. Tsimikas $(\bowtie)$

Vascular Medicine Program, University of California San Diego, 9500 Gilman Drive, BSB 1080, La Jolla, CA 92093-0682, USA

e-mail: stsimikas@ucsd.edu
$10 \%$ in the first month and up to $20 \%$ in the first year, with a $2 \%$ annual risk for the first 5 years [2]. Recurrent infarction may occur in as many as $29 \%$ of patients in 10 years following CABG [3]. In contrast to SVGs, the left internal mammary artery (LIMA) graft has a $10 \%$ closure rate in 10 years. Of note, at least $10 \%$ of percutaneous coronary interventions (PCI) are currently performed in saphenous vein grafts (SVG) lesions [1]. When patients with prior CABG present with chronically occluded SVG, the options are often limited due to the suboptimal clinical results in recanalizing these grafts percutaneously. These patients usually have 3 options: (1) percutaneous coronary intervention of the severely diseased native vessels, (2) repeat $\mathrm{CABG}$ or (3) medical therapy alone.

We present an unusual case of a patient presenting with a total occlusion of a SVG which spontaneously recanalized over a 2 month period but with a persistent focal stenosis at the distal anastomosis. The distal anastomotic stenosis was treated with a drug eluting stent and the vessel remained patent angiographically at 1 year.

\section{Case report}

The patient is a 76 year old gentleman with a history of known arteriosclerotic heart disease, status post CABG in June 1989 with a LIMA graft to the left anterior descending artery and separate SVGs to the diagonal branch and right coronary arteries. He developed recurrent angina and subsequently had a bare metal stent placed in the native left circumflex coronary artery in 2002. In 2005, he developed atypical chest pain and a sestamibi scan showed anterolateral ischemia. He underwent repeat coronary angiography which showed patent grafts and he was managed medically. 
Four days prior to the January 2007 admission, he developed acute onset retrosternal chest pain that was associated with fatigue. It lasted approximately $2 \mathrm{~h}$ and relieved by sublingual nitroglycerin. He subsequently developed atypical chest discomfort as well as exercise intolerance. He presented to medical care 4 days later with a blood pressure of $135 / 80$, pulse of 80 pulse and normal chest, heart and vascular exam. An electrocardiogram revealed loss of anterior forces, new right axis deviation and borderline $1 \mathrm{~mm}$ of ST elevation in leads I and AVL. The troponin-I level was elevated at $7.9 \mathrm{ng} / \mathrm{ml}$. Lipid profile showed total cholesterol 171, triglyceride 103, HDL 48, LDL 102. He was treated with intravenous heparin and eptifibatide and referred for urgent coronary angiography. He was maintained on aspirin $81 \mathrm{mg} /$ day and ramipril that he was already taking and started on isosorbide mononitrate, metoprolol and ezetimibe/simvastatin. Subsequent troponin levels decreased and the clinical diagnosis was acute coronary syndrome with recent myocardial infarction.

Coronary angiography showed complete thrombotic occlusion of the SVG to the diagonal branch (Fig. 1), with patent SVG to the right coronary artery with jump to the posterolateral branch. The SVG to the diagonal branch was large and completely filled with thrombus which was distinguished by multiple swirling filling defects. There was a faint trickle of flow in the graft body of the diagonal branch but the contrast did not reach the native diagonal branch. The LIMA to the LAD was patent. Left ventriculography showed new evidence of anterolateral and apical akinesis and there was a 1 to $2+$ mitral regurgitation. Because this was felt to be a functionally occluded SVG with a myocardial infarction approximately 5 days old, with no recurrent ischemia or other indication for revascularization, the eptifibatide was discontinued after the procedure after a total duration of approximately $3 \mathrm{~h}$ and the patient was treated medically and discharged on aspirin $81 \mathrm{mg} / \mathrm{d}$ as the only anti-platelet agent.

Two months after the initial hospitalization the patient developed chest tightness lasting approximately $45 \mathrm{~min}$ associated with diaphoresis and shortness of breath. ECG revealed markedly inverted T-waves in leads I and AVL as well as in leads V4-V6 which were new compared to his ECG previously. Troponin levels were normal. He was treated with heparin and eptifibatide for approximately $4 \mathrm{~h}$ prior to being taken to the cardiac catheterization laboratory. Repeat angiography showed complete patency of the previously occluded SVG to the diagonal branch (Fig. 2) with complete angiographic resolution of the thrombus. However, there was a focal $95 \%$ stenosis at the distal anastomosis, for which a drug eluting stent $(3.0 \times 18 \mathrm{~mm}$ Cypher, Cordis, Miami, Florida) was placed. The proximal segment of this stent that was in the bypass graft was treated with a $4.0 \times 8 \mathrm{~mm}$ Quantum balloon (Boston
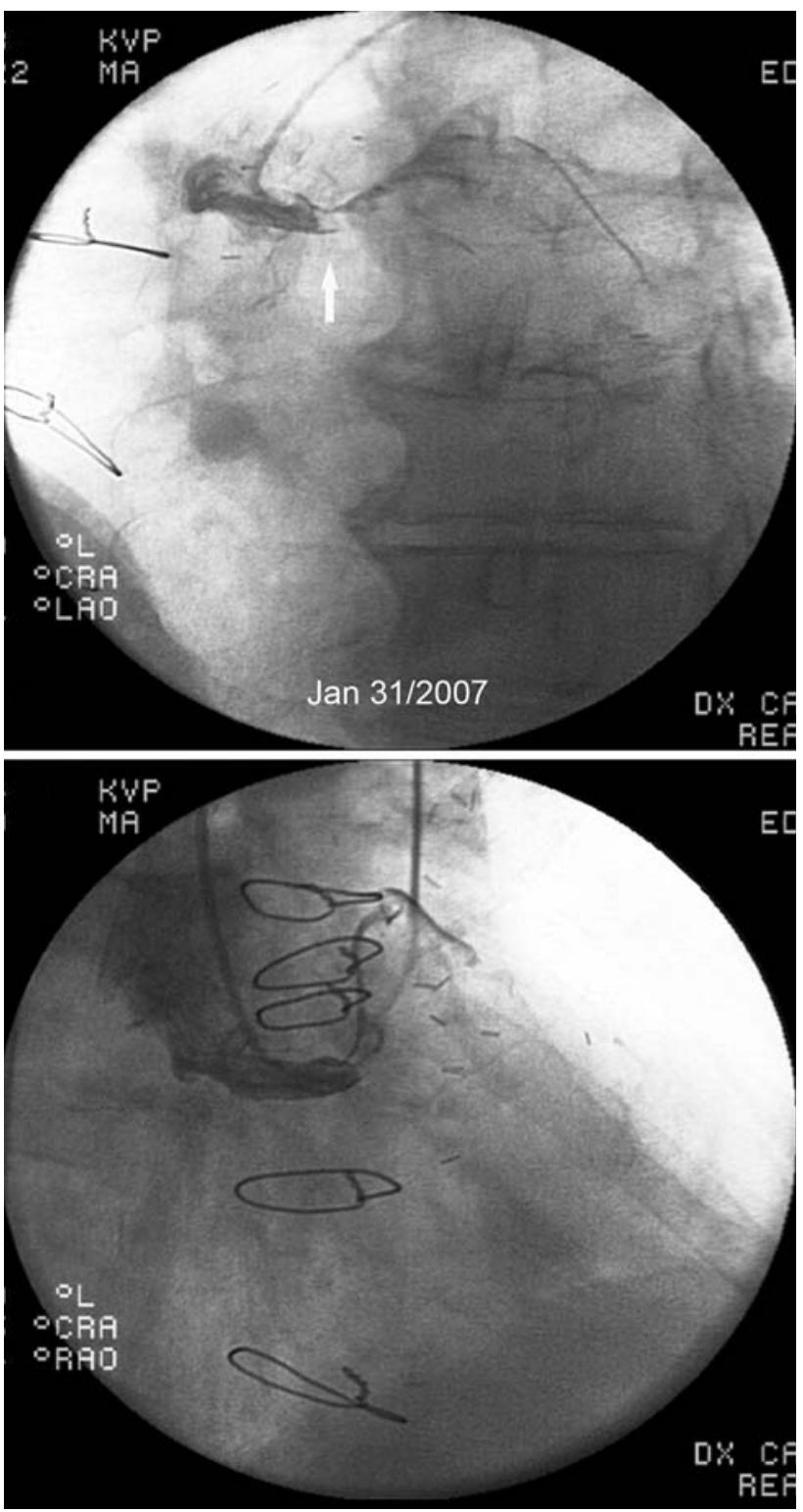

Fig. 1 Initial angiogram in January of 2007 shows complete occlusion of the SVG to diagonal branch. The white arrow points to the area of occlusive thrombus seen near the ostium of the SVG. Two views are shown (LAO cranial, RAO cranial)

Scientific, Maple Grove, Minnesota) and expanded to 16 atmospheres. The patient had transient chest discomfort during the procedure that reproduced his angina. He subsequently had complete resolution of angina and was treated with aspirin and clopidogrel indefinitely.

One year later the patient had another episode of resting but somewhat atypical chest pain and was admitted to the hospital. Initial ECG was unchanged, however $\mathrm{T}$ wave inversions were noted in V2, V3, and patient was taken to the catheterization laboratory. Angiography demonstrated no significant change from the prior cardiac catheterization, including a patent SVG-to-diagonal graft with no 

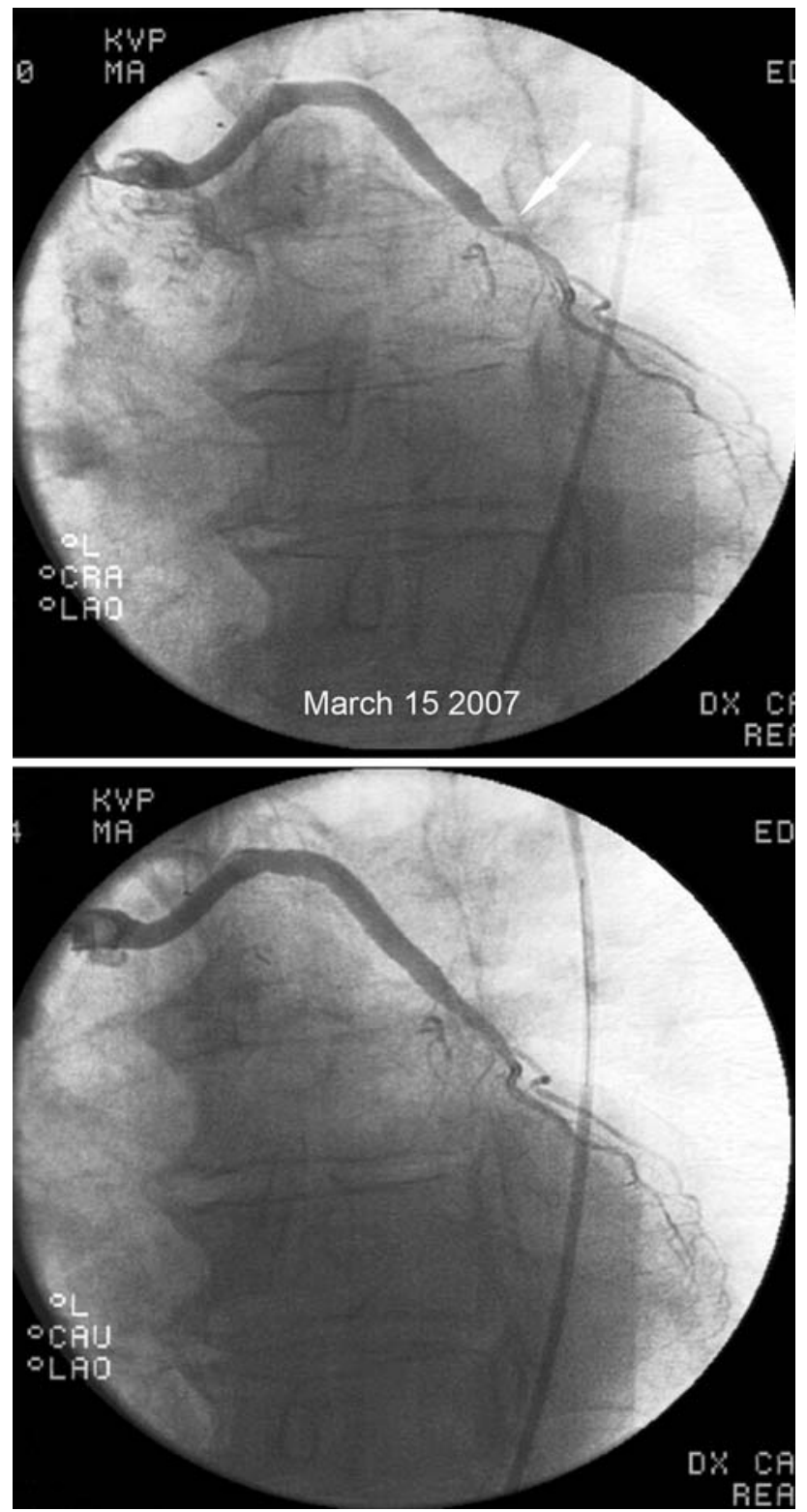

Fig. 2 Repeat angiogram performed 2 months later when the patient presented with more symptoms and negative cardiac markers. LAO cranial and caudal views shown here with white arrow demonstrating stenotic occlusion at the anastomosis site

in-stent restenosis (Fig. 3). The patient has no evidence of ischemia 24 months following the stent placement.

\section{Discussion}

This report demonstrates the rare phenomenon of complete angiographic thrombus resolution and reperfusion of a thrombotically occluded SVG following treatment with aspirin as the only outpatient anti-platelet therapy. Furthermore, the SVG had documented 1 year patency
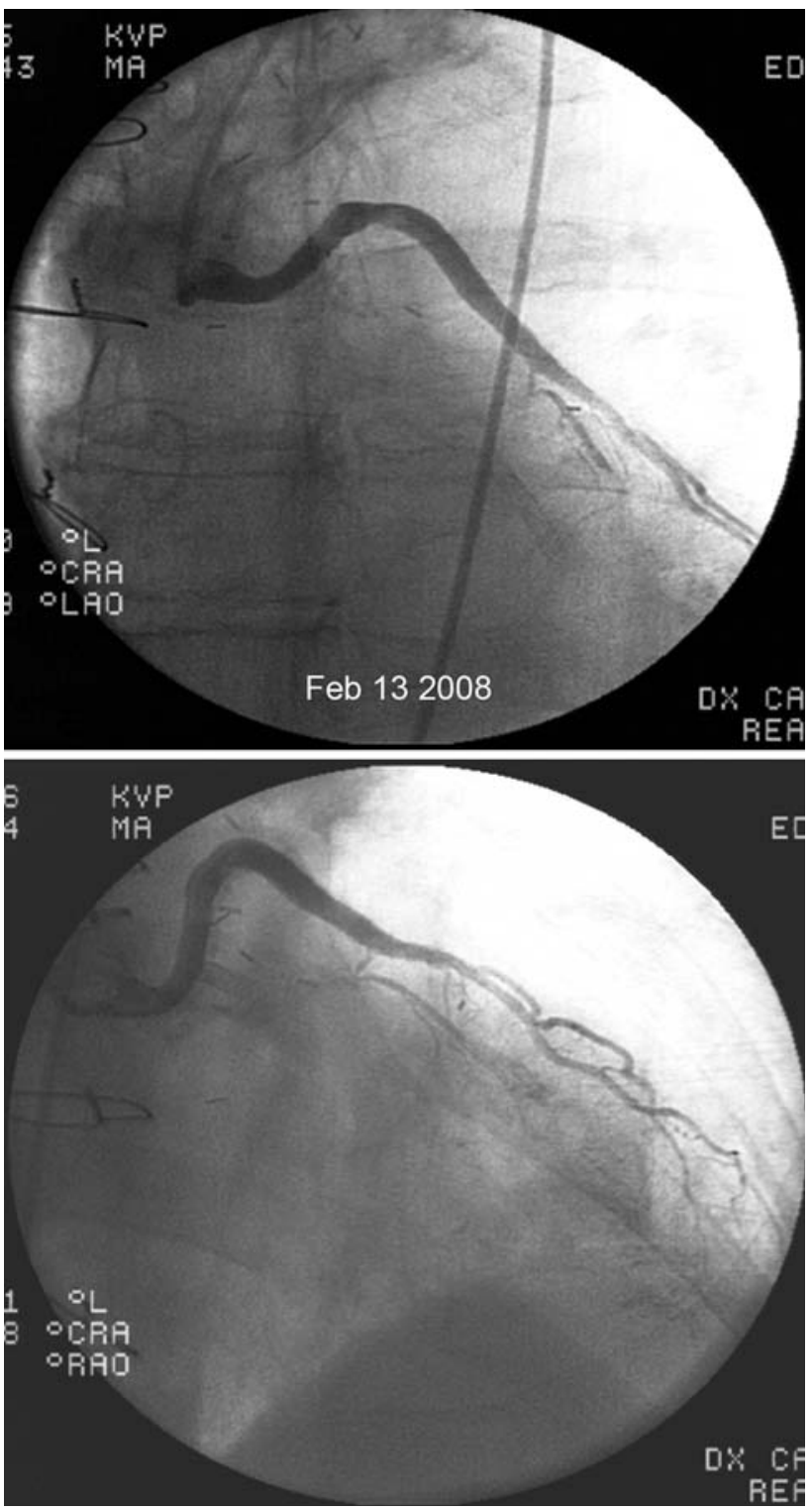

Fig. 3 Follow up angiography 1 year later demonstrating patent SVG to diagonal-branch with patent Cypher stent. Angiography is performed in LAO and RAO cranial views with angulation similar to Fig. 1

following drug eluting stent placement at the presumed site of thrombotic occlusion and a favorable clinical course for 2 years. This case suggests that a subset of patients may have the physiological capability for spontaneous fibrinolysis of even very large thrombi in completely occluded SVGs. It also reflects the therapeutic efficacy of PCI and drug eluting stents in maintaining graft patency, at least in the near term.

Vein graft infarctions usually occur in degenerated vein grafts filled with atherothrombotic debris. Their greater content of thrombus and other material such as necrotic debris predisposes them to a greater propensity for graft 
trauma, distal embolization and no-reflow phenomenon after an intervention. In the patient described in this report, repeat angiography 2 months following the initial angiogram demonstrated that the infarct related SVG was patent. Although the patient received four hours of eptifibatide prior to angiogram, it is unlikely that this had a significant "thrombolytic" effect as the SVG was totally occluded during prior coronary angiography. Prior studies in ACS or STEMI involving SVGs have not generally shown any benefit from IIb/IIIa inhibitors or even thrombolytic therapy $[4,5]$. For example, in the Mayo Clinic PCI Registry [6], results from 128 patients with prior CABG with primary PCI in AMI patients showed that when the treated vessel was a SVG, there was a lower success rate, with increased inability to completely recanalize the SVG along with increased risk of distal embolization, when compared to a native vessel intervention. Similarly, in the PAMI-2 trial where the infarct related artery was an SVG rather than a native coronary artery, both TIMI-3 flow grade (70.2\% vs. $94.3 \%)$ and 6-month mortality (14.3\% vs. $4.1 \%)$ were worse in patients with versus without previous CABG [7]. Similar outcomes were noted in the GUSTO-I trial in 1784 patients with STEMI [8]. Nonetheless, in a subset of patients, such as the one presented here, they may enhance partial fibrinolysis as has been suggested by upfront IIb/IIIa inhibitor use in STEMIs showing enhanced TIMI III flow on angiography prior to PCI [9]. It is intriguing to speculate that this process may be enhanced by novel anti-platelet agents that are being developed [10].

In SVG infarct cases, the decision to proceed to an intervention is made after taking into consideration infarct size and duration, patient condition, thrombus burden, and vessel anatomy. Recanalization of the native coronary artery to which the SVG was anastomosed may be a better option. In our case, no initial intervention was performed for the occluded SVG due to the large thrombus burden in the length of the graft and the regression of symptoms. Furthermore the native diagonal branch was totally occluded proximally and it was felt that it could not be recanalized.

Only two previous cases have been reported of spontaneous reperfusion of a SVG related to an AMI. The first is a patient with a NSTEMI due to SVG thrombosis 1 month after discontinuation of antiplatelet therapy [11]. The graft was initially filled with thrombus but was patent 6 days later. The second case is a patient with a STEMI due to an occlusion of one SVG, who was treated with a stent to his native LAD. Three months later the graft was patent but the native LAD occluded [12]. Our case represents the longest documented patency of a spontaneously recanalized graft, albeit it was also treated with a drug eluting stent at the distal anastomosis which likely has helped maintain patency. Spontaneous reperfusion of an infarct related native coronary artery is not uncommon, particularly in this era of aggressive in-hospital anti-thrombotic therapy, and is associated with greater myocardial salvage and resolution of chest pain [13].

This observation of "spontaneous" reperfusion is highly intriguing, particularly in an elderly individual, an age group where impaired fibrinolysis is common [14]. It is possible that aspirin by itself potentiated a fibrinolytic effect, as demonstrated in the ISIS-2 thrombolytic trial where the aspirin alone was associated improved clinical outcomes [15]. It has also been reported that the local profibrinolytic response in coronary arteries, by net coronary release of tissue-type plasminogen activator (t-PA) following induced myocardial ischemia in pigs, could be a useful defense against coronary thromboembolic events. In fact, higher levels of t-PA are noted in ST-segment elevation myocardial infarction, and are paradoxically associated with worse prognosis [16, 17]. Possible mechanisms of spontaneous recanalization include the release of factors, activators and inhibitors of fibrinolysis, from the endothelium, neutrophils and monocytes [18]. The role of thienopyridines such as clopidogrel in enhancing reperfusion has not been demonstrated, but one would predict it would be additive to aspirin, based on recent trials [19].

In conclusion, we describe an unusual case of spontaneous reperfusion of an SVG, subsequent treatment of a residual stenosis with a drug eluting stent and a favorable 2 year outcome. Understanding the underlying mechanisms of enhanced thrombolysis may help discover new insights into sustained graft patency that may improve long term outcomes of patients undergoing CABG. Although it has not been formally evaluated yet, defining the long-term efficacy of dual anti-platelet therapy in patients in preventing events in patients who have undergone CABG is a worthwhile clinical question that should be investigated.

Open Access This article is distributed under the terms of the Creative Commons Attribution Noncommercial License which permits any noncommercial use, distribution, and reproduction in any medium, provided the original author(s) and source are credited.

\section{References}

1. Baim DS (2003) Percutaneous treatment of saphenous vein graft disease: the ongoing challenge. J Am Coll Cardiol 42:1370-1372. doi:10.1016/s0735-1097(03)01039-8

2. Fitzgibbon GM, Kafka HP, Leach AJ, Keon WJ, Hooper GD, Burton JR (1996) Coronary artery bypass grafting fate and angiographic follow up of 5065 grafts related to survival and reoperation in 1388 patients in 25 years. J Am Coll Cardiol 28:616-626. doi:10.1016/0735-1097(96)00206-9

3. Brooks MM, Alderman EL, Bates E, Bourassa M, Califf RM, Chaitman BR, Detre KM, Feit F, Frye RL, Gibbons RJ, Hardison 
RM, Hlatky MA, Holmes DR, Jacobs AK, Kelsey SF, Krauland M, Rogers WJ, Hartzell VS, Schwartz L, Sutton-Krauland K, Rogers WJ, Schaff HV, Schwartz L, Sutton-Tyrrell K, William DO, Whitlow PK (2007) The final 10-year follow-up results from the BARI randomized trial. J Am Coll Cardiol 49:1600-1606. doi:10.1016/j.jacc.2006.11.048

4. Roffi M, Mukherjee D, Chew DP, Bhatt DL, Cho L, Robbins MA, Ziada KM, Brennan DM, Ellis SG, Topol EJ (2002) Lack of benefit from intravenous platelet glycoprotein IIb/IIIa receptor inhibition as adjunctive treatment for percutaneous interventions of aortocoronary bypass grafts: a pooled analysis of five randomized clinical trials. Circulation 106:3063-3067. doi:10.1161/ 01.cir.0000041250.89627.a9

5. Reiner JS, Lundergan CF, Kopecky SL (1996) Ineffectiveness of thrombolysis for acute MI following vein graft occlusion (abstr). Circulation 94(Suppl I):I570

6. Al Suwaidi J, Velianou JL, Berger PB, Mathew V, Garratt KN, Reeder GS, Grill DE, Holmes DR Jr (2001) Primary percutaneous coronary interventions in patients with acute myocardial infarction and prior coronary artery bypass grafting. Am Heart $\mathbf{J}$ 142:452-459. doi:10.1067/mhj.2001.117319

7. Stone GW, Brodie BR, Griffin JJ, Grines L, Boura J, O’Neill WW, Grines CL (2000) Clinical and angiographic outcomes in patients with previous coronary artery bypass graft surgery treated with primary balloon angioplasty for acute myocardial infraction, PAMI-2 Trial. J Am Coll Cardiol 35:605-611. doi:10.1016/ s0735-1097(99)00605-1

8. Labinaz M, Sketch MH, Ellis SG, Abramowitz BM, Stebbins AL, Peiper KS, Holmes DR Jr, Califf RM, Topol EJ (2001) Outcome of acute ST-segment elevation myocardial infarction in patients with prior coronary artery bypass surgery receiving thrombolytic therapy. Am Heart J 141:469-477. doi:10.1067/mhj.2001.112779

9. Beygui F, Montalescot G (2005) The use of GP IIb/IIIa inhibitor into new perspectives: pre-catheterization laboratory administration. Eur Heart J Suppl 7:I10-I14. doi:10.1093/eurheartj/sui062

10. Angiolillo DJ, Capranzano P (2008) Pharmacology of emerging novel platelet inhibitors. Am Heart J 156:S10-S15. doi:10.1016/ j.ahj.2008.06.004
11. Dangoisse V, Colizza F (1990) Spontaneous thrombolysis in a suboccluded saphenous vein graft. Am Heart J 119:394-396. doi: 10.1016/S0002-8703(05)80034-1

12. Shah RA, Khanal S, Kugelmass A (2006) Spontaneous late thrombolysis of an occluded saphenous vein graft subsequent to acute myocardial infarction treated with percutaneous coronary intervention to the native culprit vessel. J Interv Cardiol 19:178 182. doi:10.1111/j.1540-8183.2006.00129.x

13. Rimar D, Crystal E, Battler A, Gottlieb S, Friemark D, Hod H, Boyko V, Mandelzweig L, Behar S, Leor J (2002) Improved prognosis of patients with clinical markers of spontaneous reperfusion during acute myocardial infarction. Heart 88:352-356. doi: 10.1136/heart.88.4.352

14. Gharacholou SM, Becker RC (2009) Hemostasis and thrombosis in older adults. J Thromb Thrombolysis 27:249-251. doi:10.1007/ s11239-009-0308-4

15. ISIS-2 (Second International Study of Infarct Survival) Collaborative Group (1988) Randomised trial of intravenous streptokinase, oral aspirin, both or neither among 17, 187 cases of suspected acute myocardial infarction ISIS-2. Lancet 332:349-360. doi:10.1016/ S0140-6736(88)92833-4

16. Jansson JH, Olofsson BO, Nilsson TK (1993) Predictive value of tissue plasminogen activator mass concentration on long-term mortality in patients with coronary artery disease: a 7-year follow-up. Circulation 88:2030-2034

17. Hamsten A, Wiman B, de Faire U, Blombäck M (1985) Increased plasma levels of a rapid inhibitor of tissue plasminogen activator in young survivors of myocardial infarction. N Engl J Med 313: $1557-1563$

18. Osterlund B, Andersson B, Haggmark S, Jern C, Johansson G, Seeman-Lodding, Biber B (2002) Myocardial ischemia induces coronary t-PA release in the pig. Acta Anaesthesiol Scand 46:271278. doi:10.1034/j.1399-6576.2002.t01-1-460308

19. Doggrell SA (2005) CLARITY about the use of clopidogrel in patients with acute coronary syndromes and myocardial infarction. Expert Opin Pharmacother 6:1761-1764. doi:10.1517/14656566. 6.10 .1761 